\title{
FEM analysis of the temperature distribution of CFRTP pipe mold with direct resistance heating
}

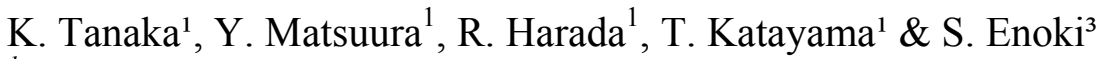 \\ ${ }^{I}$ Department of Biomedical Engineering, Doshisha University, Japan \\ ${ }^{2}$ Department of Mechanical Engineering, \\ Nara National College of Technology, Japan
}

\begin{abstract}
In the automobile industry, from the point of preventing global warming, the mass reduction of automotive bodies has become more important than ever. Especially automotive weight lightening by using Carbon Fiber Reinforced Thermoplastics (CFRTP), which has advantage of high-specific strength and high-specific modulus, has received much attention. A lot of pipe-shaped materials are used for a car. For CFRTP pipe molding, a low-cost and high-speed molding method is required. Using high-frequency electric resistance heating allows heating the mold surface rapidly. Rapid heating of the mold can reduce production cycle time. The electrical energy of this heating method is less than that of traditional heating methods, and therefore the reduction in production cost is expected. In molding of CFRTP, uniformity of temperature distribution is one of the important issues to be solved. In this study, temperature distribution of CFRTP pipe molding by direct resistance heating was evaluated by FEM analysis. In direct resistance heating, the temperature distribution of the mold depends on the shape of electrodes and electric frequency. Influence of the shape of electrodes and electric frequency on the temperature distribution of the mold is revealed by using FEM analysis.
\end{abstract}

Keywords: CFRTP pipe, FEM analysis, temperature distribution, skin effect, high-frequency electric resistance heating. 


\section{Introduction}

In the auto industry, light-weighting of the body improves gas mileage of the car. Because Carbon Fiber Reinforced Plastics (CFRP) has superior mechanical characteristics such as high-specific strength and high-specific modulus, they are expected as light-weighting materials of the mass-produced cars $[1,2]$. A lot of high-strength materials of pipe shapes are used for automotive parts, which can be substituted by Carbon Fiber Reinforced Thermoplastics (CFRTP). The high-speed molding method to mass-produce CFRTP pipes has not yet been established. As the heating method for the mold used for CFRTP pipe molding, direct resistance heating using alternate current was applied. With this method, electric current passes near the mold surface intensively by skin effect and heats the mold by Joule heating. Direct resistance heating can reduce cost by the simplification of facilities in comparison with the induction heating method and to improve energy efficiency $[3,4]$. However, direct resistance heating method has a drawback regarding the temperature distribution of the mold. In the experiment of molding CFRTP pipe using Non-woven Stitched Multi-axial Cloth (NSMC), inhomogeneity in temperature distribution causes degradation in impregnation of the resin [5]. By using finite element analysis, temperature distribution of the mold becomes predictable [6,7]. Factors to influence the temperature distribution of the mold include arrangement of electrode and frequency of alternate current [8,9]. In this study, influence of the shape of electrodes and electric frequency on the temperature distribution of the mold heated by direct resistance heating is revealed by using FEM analysis.

\section{Heating method}

The high frequency direct resistance heating is a technique used for heattreatment and welding of metals. By using alternate current, the surface of the mold is heated intensively by skin effect. The skin effect is expressed in the following equation

$$
d=\sqrt{\frac{1}{\pi f \mu \sigma}}
$$

where $d$ is skin depth, $f$ is current frequency, $\mu$ is magnetic permeability, and $\sigma$ is conductivity. By using higher frequency, it is possible to heat the surface of the mold more intensively. Since high frequency direct resistance heating does not require a coil such as induction, it is possible to reduce the equipment cost. Ferritic stainless steel, hereinafter referred to as SUS430 (JIS G 4303), is used for the mold due to its high magnetic permeability. In this study, the definition that temperature distribution is uniform is set to the range of $\pm 5^{\circ} \mathrm{C}$ in temperature difference of the mold surface. The pipe is molded by surrounding with inner mold and outer mold as shown in Fig. 1. In this method, temperature distribution on the surface of the inner mold is the most important to mold CFRTP. 


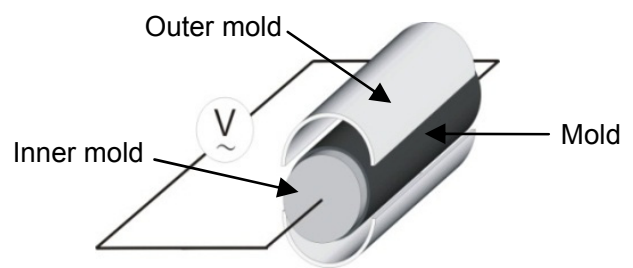

Figure 1: Schematic drawing of skin effect.

\section{FEM analysis}

\subsection{Governing equation}

COMSOL Multiphysics is used for finite-element analysis. The modules used in this model were Electric and Induction Currents (AC/DC Module) and General Heat Transfer (Heat Transfer Module). The heat equation in General Heat Transfer is expressed in the following equation.

$$
\delta_{t s} \rho C_{p} \frac{\partial T}{\partial t}-\nabla(k \nabla T)=Q
$$

where $\delta_{t s}$ is time scaling coefficient, $\rho$ is density, $C_{p}$ is specific heat capacity, $T$ is temperature, $k$ is thermal conductivity, and $Q$ is heat source. The analytic formula of Electric and Induction Currents is expressed in the following equation

$$
\begin{gathered}
-\nabla\left(i \omega \sigma-\omega^{2} \varepsilon_{0} \varepsilon_{r}\right) A-\sigma \times(\nabla \times A)+\left(\sigma+i \omega \varepsilon_{0} \varepsilon_{r}\right) \nabla V-J^{e}=0 \\
\left(i \omega \sigma-\omega^{2} \varepsilon_{0} \varepsilon_{r}\right) A+\nabla \times\left(\mu_{0}^{-1} \mu_{r}^{-1} \nabla \times A\right)-\sigma v \times\left(\sigma+i \omega \varepsilon_{0} \varepsilon_{r}\right) \nabla V=J^{e}
\end{gathered}
$$

where $\varepsilon_{0}$ is electrical conductivity of the air, $\varepsilon_{r}$ is electrical conductivity of the conductor, $A$ is magnetic field, $\mu_{0}$ is magnetic permeability of the air, $\mu_{r}$ is magnetic permeability of the conductor, $V$ is electric potential, $v$ is velocity, and $J^{e}$ is current density. Temperature distribution of the mold by using these equations is evaluated.

\subsection{Analytical model}

The mold is columnar form having $30 \mathrm{~mm}$ in diameter, and $300 \mathrm{~mm}$ in length. In order to obtain sufficient skin effect, SUS430 which is a ferrite stainless steel with ferromagnetism is used for mold material. Electrodes made of copper are set at the both ends of the mold. Two types of electrodes, Flat and Rod-shaped as shown in Fig. 2, are used. The size of the Flat electrode is $2 \mathrm{~mm} \times 30 \mathrm{~mm} \times$ $50 \mathrm{~mm}$ and that of the Rod-shaped electrode is $30 \mathrm{~mm} \times 30 \mathrm{~mm} \times 50 \mathrm{~mm}$. The 
physical properties of each material are shown in Table 1. In consideration of heat radiation in the air, the layer of the air is set around molds. The size of the layer of the air for the Flat electrode model is $150 \mathrm{~mm} \times 250 \mathrm{~mm} \times 400 \mathrm{~mm}$ and that of the layer of the air for the Rod-shaped electrode model is $75 \mathrm{~mm} \times 75 \mathrm{~mm}$ $\times 450 \mathrm{~mm}$. The initial temperature is set to $20^{\circ} \mathrm{C}$. Heating time is set at 60 seconds. The frequencies of alternate current are $0.5 \mathrm{kHz}, 1 \mathrm{kHz}, 10 \mathrm{kHz}$, $25 \mathrm{kHz}$ and $50 \mathrm{kHz}$ with the output power of $3.0 \mathrm{~kW}$. Tetrahedral elements are used for elements. The layer of the air is set around the mold so as to radiate heat to the air. A number of elements is 15717 in Flat electrode model, and 14589 in the Rod- shaped electrode model.

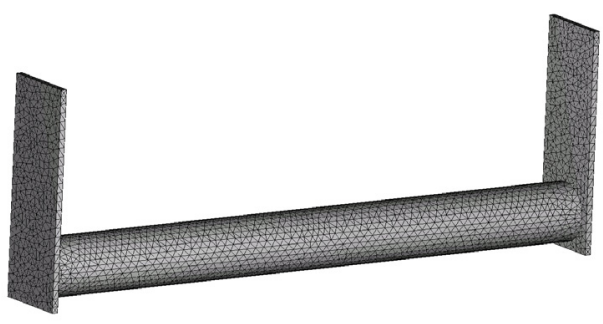

(a)

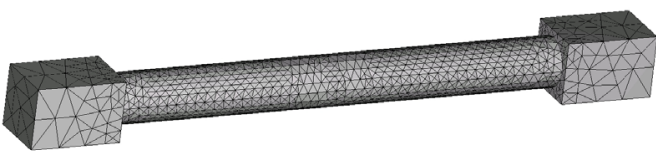

(b)

Figure 2: FEM models, (a) Flat electrode model, (b) Rod- shaped electrode model.

Table 1: Electrical properties of each material.

\begin{tabular}{c|c|c|c|c}
\hline & $\begin{array}{c}\text { Relative } \\
\text { magnetic } \\
\text { permeability }\end{array}$ & $\begin{array}{c}\text { Electric } \\
\text { conductivity } \\
{[\mathrm{S} / \mathrm{m}]}\end{array}$ & $\begin{array}{c}\text { Relative } \\
\text { permittivity }\end{array}$ & $\begin{array}{c}\text { Thermal } \\
\text { conductivity } \\
{[\mathrm{W} /(\mathrm{m} \cdot \mathrm{K})]}\end{array}$ \\
\hline Air & 1 & 0 & 1 & 0.257 \\
\hline Copper & 1 & $5.998 \times 10^{7}$ & 1 & 400 \\
\hline SUS430 & 122.4 & $1.666 \times 10^{6}$ & 1 & 25.6 \\
\hline
\end{tabular}




\section{Results and discussions}

\subsection{Flat electrode model}

Fig. 3 shows the temperature distribution of the mold surface for the flat electrode model with the frequencies of $5 \mathrm{kHz}$ and $50 \mathrm{KHz}$. In Fig. 4, Line A and Line B are illustrated on the mold surface. Fig. 5 shows temperature profiles of Line A and Line B. When frequencies of alternate current are $50 \mathrm{kHz}, 25 \mathrm{kHz}$, $10 \mathrm{kHz}$ and $5 \mathrm{kHz}$, at the both ends of the mold, temperature of the electrode connected side (Line A) is higher; that of the opposite side (Line B) is lower. Temperature distribution in frequencies of $1 \mathrm{kHz}$ and $0.5 \mathrm{kHz}$ is in a uniform temperature in $\pm 5^{\circ} \mathrm{C}$ on the range of $200 \mathrm{~mm}$ in the center of the mold. The reason is considered to be the influence of the magnetic field that generated by current flowing through the electrodes.

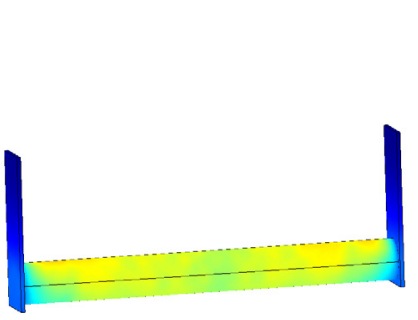

(a)

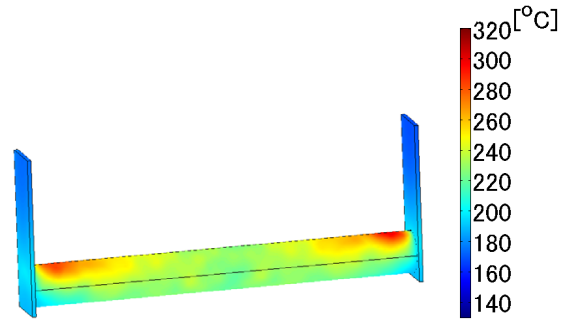

(b)

Figure 3: Temperature distribution, (a) $5 \mathrm{kHz}$, (b) $50 \mathrm{kHz}$.

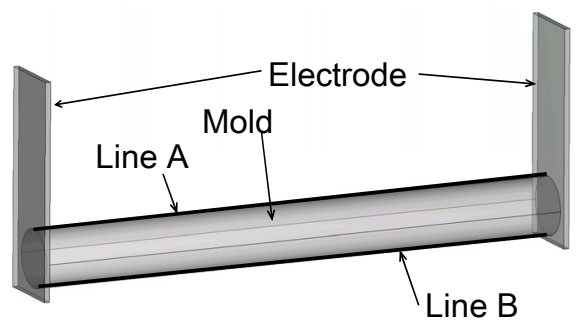

Figure 4: Positions of Line A and Line B. 


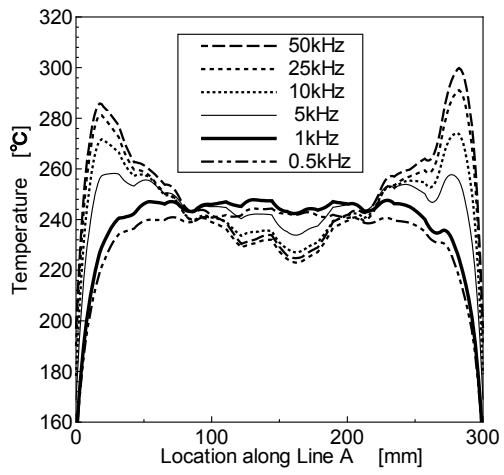

(a)

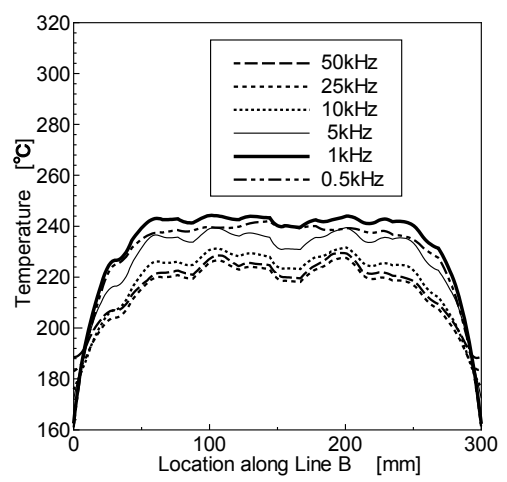

(b)

Figure 5: Temperature distribution of flat electrode model, (a) temperature profiles in Line A, (b) temperature profiles in Line B.

\subsection{Rod-shaped electrode model}

Fig. 6 shows the temperature distribution of the mold surface for the Rod-shaped electrode model with the frequencies of $5 \mathrm{kHz}$ and $50 \mathrm{KHz}$. In Fig. 7, Line $\mathrm{C}$ is illustrated on the mold surface. Fig. 8 shows temperature profiles of Line C. Temperature differences in the frequencies of $0.5 \mathrm{kHz}, 1 \mathrm{kHz}$, and $5 \mathrm{kHz}$ are in $\pm 5^{\circ} \mathrm{C}$ on the range of $200 \mathrm{~mm}$ in the center of the mold. With the flat plate-shaped electrode, temperature distribution has deflection by the position relations of the electrode. Thus, the Rod-shaped electrode is suitable to get uniform temperature distribution. At the both ends of the mold, surface temperature is lower than the center area due to the heat radiation to electrodes.

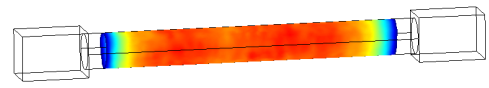

(a)

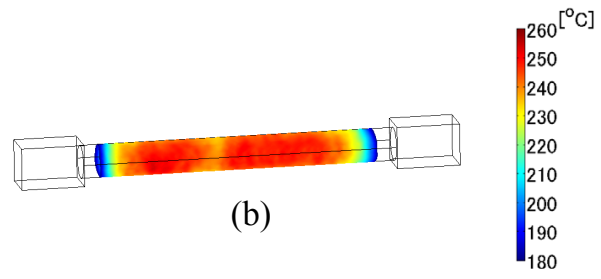

Figure 6: Temperature distribution, (a) $5 \mathrm{kHz}$, (b) $50 \mathrm{kHz}$.

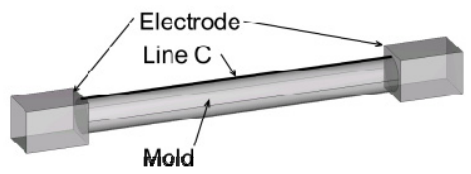

Figure 7: Position of Line C. 


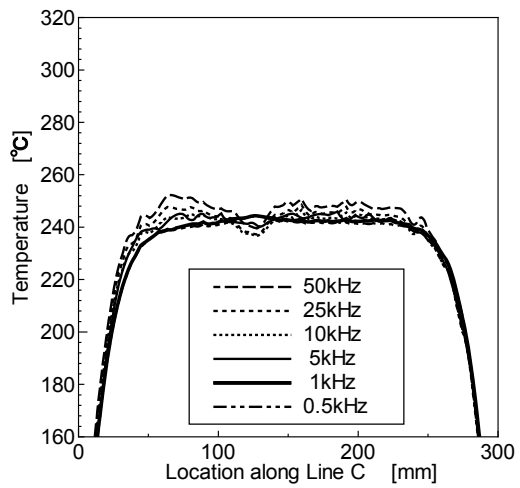

Figure 8: Temperature distribution of rod-shaped electrode model.

\section{Conclusions}

The effect of the frequency and the shape of the electrode on temperature distribution of the mold heated by direct resistance heating is revealed by FEM analysis. The investigation yields the following conclusions.

1. For the Flat electrode, temperature distribution in frequencies of $1 \mathrm{kHz}$ and $0.5 \mathrm{kHz}$ is in a uniform temperature in $\pm 5^{\circ} \mathrm{C}$ on the range of $200 \mathrm{~mm}$ in the center of the mold.

2. For the Rod-shaped electrode, temperature distribution in frequencies of $1 \mathrm{kHz}, 0.5 \mathrm{kHz}$, and $5 \mathrm{kHz}$ is in a uniform temperature in $\pm 5^{\circ} \mathrm{C}$ on the range of $200 \mathrm{~mm}$ in the center of the mold.

3. For the flat plate-shaped electrode, temperature distribution has deflection by the position relations of the electrode. The Rod-shaped electrode is suitable to get uniform temperature distribution.

\section{Acknowledgement}

This study was partially supported by the High Technological Research Project on "Research and Development Center for Advanced Composite Materials" of Doshisha University and the Ministry of Education, Culture, Sports, Science and Technology, Japan.

\section{References}

[1] R. Shida, K. Tsumuraya, S. Nakatsuka and J. Takahashi, Effect of automobile lightening by CFRP on the world energy saving, The Ninth Japan International SAMPE symposium, pp. 8-13, 2005.

[2] A. Nakai, Application of Fiber Reinforced Plastics to Advanced Vehicle for Energy Saving Society, SEN'I GAKKAISHI, Vol. 65, No. 1, pp. 31-32, 2009. 
[3] K. Tanaka, R. Harada, T. Uemura, T. Katayama \& H. Kuwahara, Rapid Pipe Moulding Process of Carbon Fibre Reinforced Thermoplastics by Highfrequency Direct Resistance Heating, WIT Transactions on the Built Environment, Vol. 112, pp. 133-139, 2010.

[4] K. Tanaka, R. Harada, T. Uemura, T. Katayama, Development of rapid pipe Molding process for carbon fiber reinforced Thermoplastics by direct resistance heating, International Journal of Modern Physics, Vol. 6, pp. 616-621, 2012.

[5] K. Tanaka, N. Kohashi, Y. Kinoshita, T. Katayama, K. Uno, Compression Molding of Carbon Fiber Reinforced Thermoplastics Using Non-Woven Stitched Multi-Axial Cloth by Means of Induction Heating System, J. Soc. Mater. Sci., Japan, Vol. 58, No. 7, pp. 642-648, 2009.

[6] K. Uemura, S. Isobe, A. Noguchi, Estimation of temperature profile at sequence ohmic heating by Finite element method, Nippon Shokuhin Kagaku Kogaku Kaishi, Vol. 43, No. 11, pp. 1190-1196, 1996.

[7] K. Mori, S. Maki, N. Arisawa, K. Ueno, Y. Hokazono, T. Yamazaki, Resistance heating of side wall for warm and hot spline forming of cup, The japan society for technology of plasticity, Vol. 49, No. 574, pp. 1106-1110, 2008.

[8] K. Fukutani, K. Umetsu, T. Isobe, Study of Variable frequency induction heating in steel making process, IEEJ Trans IA, Vol. 130, No. 10, 2010.

[9] S. Jang, S K Cho, S Lee, H W Cho, H C Park, Thermal analysis of induction heating roll with heat pipes, IEEE transactions on magnetics, Vol. 39, No. 5, 2003. 